\title{
The Impact of COVID-19 Pandemic on Tertiary Education in Bangladesh: Students' Perspectives
}

\author{
Sushmita Dutta, Marzia Khatan Smita \\ Institute of Education and Research, University of Chittagong, Chittagong, Bangladesh \\ Email: sushmitadutta777@cu.ac.bd,mk.marzia@gmail.com
}

How to cite this paper: Dutta, S., \& Smita, M. K. (2020). The Impact of COVID-19 Pandemic on Tertiary Education in Bangladesh: Students' Perspectives. Open Journal of Social Sciences, 8, 53-68. https://doi.org/10.4236/jss.2020.89004

Received: August 10, 2020

Accepted: September 1, 2020

Published: September 4, 2020

Copyright (อ 2020 by author(s) and Scientific Research Publishing Inc. This work is licensed under the Creative Commons Attribution International License (CC BY 4.0).

http://creativecommons.org/licenses/by/4.0/

\section{(c) (i) Open Access}

\begin{abstract}
The present study sought to explore the impact of COVID-19 pandemic on tertiary education in Bangladesh through the students' perspectives by using a qualitative research design. The participants were fifty university students who took part in semi-structured interviews. The thematic analysis method was used for data analysis. Numerous unprecedented disruptions in students' learning, decrease in motivation and study hours, and various physical, mental, and economic problems regarding academic studies were prominently found in this study. The study findings concerning online education such as unavailability of electronic devices, limited access to the internet, high cost of internet, low speed of internet, and difficulties in using online platforms were also provided valuable insights into the present scenario of online tertiary education in Bangladesh as COVID-19 is continuing. It is recommended that necessary steps should be taken to improve internet speed and provide free or cheaper internet packages and technical training on online education to tertiary-level students in Bangladesh in this COVID-19 period.
\end{abstract}

\section{Keywords}

COVID-19, Pandemic, Tertiary Education, Bangladesh, Closure of Educational Institutions

\section{Introduction}

In 2020, the fear that grips the world's people is the COVID-19 pandemic. The infectious disease COVID-19 was first detected in December 2019 in Wuhan, Hubei province, China (WHO, 2020). This COVID-19 pandemic has already impaired global healthcare systems as well as affected every aspect of human life. For reducing the spread of the disease infection, governments of numerous 
countries have emphasized taking several unprecedented preventive measures like strengthening health facilities, closure of educational institutions, offices, markets, restaurants, museums, movie theatres, etc., prohibition on social gatherings, border shutdown, and travel restrictions. These social distancing measures have a substantive effect on education, health, business, tourism, and so on.

On March 8, 2020, Bangladesh diagnosed its first three cases of COVID-19 (IEDCR, 2020). Like many other countries, the government of Bangladesh decided to close the educational institutions as part of preventive measures against the spread of COVID-19 pandemic. All educational institutions in Bangladesh have remained close since March 17, 2020 to the time of writing this paper. So the students from primary to tertiary level are being compelled to stay at home instead of attending classes in educational institutions to maintain social distancing.

Previous pieces of literature showed the closure of educational institutions as an effective strategy for breaking the critical transmission chain during the pandemic (Earn et al., 2012; Kawano \& Kakehashi, 2015; Luca et al., 2018; Wu et al., 2010). Still, it has negative consequences on students' academic study, including learning interruptions, disruption to assessment, and the impact is more severe on students from disadvantaged backgrounds (UNESCO, 2020a). According to the UNESCO (2020b), the nationwide closure of schools, colleges, universities and other educational institutions, happened for the COVID-19, are adversely impacting on over $60 \%$ of the world's student population.

In this COVID-19 period, among the world's student population, tertiary-level students are experiencing educational disruptions on an unprecedented scale. The research demonstrated that this COVID-19 situation induced concerns in students about academic activities along with social and economic affairs and fear of infection (Al-Tammemi et al., 2020). The pandemic heavily hit the tertiary-level students' social life as no meeting with friends and relatives (Cao et al., 2020), financial condition as losing of part-time jobs and emotional health as increasing frustration, anxiety and boredom (Brooks et al., 2020) and academic life as growing worried about future education and career (Cao et al., 2020).

Students experienced significant educational disruptions as the pandemic interfered with their academic functioning (Charles et al., 2020). Since the closure of tertiary-level educational institutions suspended face-to-face teaching-learning sessions, it interrupted the regular flow of academic programs (Jacob et al., 2020). The delay in re-opening educational institutions can negatively affect their mental state and academic growth (Chandasiri, 2020). The long-time home quarantine period caused disturbance and deterioration in students' study habits and performance of work, which eventually resulted in the growth of stress and dysfunctional learning behaviors (Meo et al., 2020). Major interruptions occurred in students' learning, as many internal and public assessments were postponed or canceled (Burgess \& Sievertsen, 2020). To diminish the disruptions in tertiary education, a significant shifting of many educational institutions to 
emergency online learning programs from traditional face-to-face learning programs has been noticed during the COVID-19 situation. But research showed that students were uncomfortable and distressed by online learning strategy (Al-Tammemi et al., 2020). They faced challenges in switching to online lectures, adjusting in new online assessment methods and workloads, communicating with teachers, and dealing with many online education issues like unavailability of electronic devices, no internet access, high cost of internet, etc. (Owusu-Fordjour et al., 2020). Even scientific researches held on and educational conferences canceled or moved online, which created barriers for students to networking opportunities for scientific communication and job seeking (Nicola et al., 2020).

In Bangladesh, there are four million students in over 5000 tertiary educational institutions, including public and private universities, professional institutions, and affiliated colleges (Ahmed, 2020). Considering the health issue, the government also opted to use online education strategy as an immediate measure for continuing the teaching-learning process during the temporary closure of educational institutions. It can be said that the COVID-19 has also spread its effects on tertiary education in Bangladesh. Though there exist a number of research papers on COVID-19 associated with educational studies, to the best knowledge of the researchers, very little research has been done concerning the field of tertiary education in Bangladesh. So there is an urgent necessity to evaluate empirical data on the effects of COVID-19 on tertiary-level education in Bangladesh and its students for determining the educational disruptions created by the COVID-19. Therefore, the present research aimed at exploring the impact of COVID-19 on tertiary education in Bangladesh through the perspectives of tertiary-level students.

\section{Research Method}

A phenomenological qualitative research design was employed for this study, which was appropriate for the research as it can provide an in-depth understanding of the nature of a particular phenomenon (Creswell, 2013).

\subsection{Participants}

To obtain enough data to address the research question, fifty university students were selected for the research employing convenience sampling. They were the students of four universities-one public university and one private university from each city of Dhaka and Chittagong in Bangladesh. Among 50 students, 24 were male students, and 26 were female. Their age ranged from 18 to 25 years, with a mean of 21 years. As for the year of study, 6 students were in their 1st year of study, 7 in their 2 nd year, 7 in their 3 rd year, and 3 in their 4 th year. A total of twenty-three participants were students of Bachelor degree programs, and twenty-seven were in Master degree programs. The students belonged to different subjects: three students were in Physics, three were in Computer science and engineering, and forty-four were in Education. 


\subsection{Data Collection Instrument}

A semi-structured interview protocol was developed for this research by the researchers. The semi-structured interview instrument was chosen for data collection as a suitable interviewing format for this qualitative research because in-depth data can be elicited through it in which the participants have to answer preset open-ended questions about the study matters (DiCicco-Bloom \& Crabtree, 2006). The instrument had questions on the effects of COVID-19 on tertiary education. It was given to two experts in science education for the determination of validity and clarity of the items. Several probing questions related to the objective of the study were asked to the participants and each interview lasted for 30 to 40 minutes. Interviews were conducted via telephone, considering the COVID-19 crisis period. A phone call recording application for the Android phone downloaded from the Google play store to record the telephone interviews. Then interviews were transcribed. Two research assistants did the transcriptions and coding of data.

\subsection{Data Analysis Method}

The six steps of thematic analysis method were followed for data analysis considering the qualitative nature of the study as it is the widely used qualitative research data analysis method for identifying, analyzing, and reporting patterns within data (Braun \& Clarke, 2006). The interview transcription process was followed in documenting each conversation. The two researchers read each transcript and marked themes with codes independently. Inductive and deductive approaches were used to identify and characterize themes that emerged from the data. Then the researchers finalized the major themes and included the minor themes into them.

\section{Findings}

Seven themes emerged from the analysis of the qualitative data of this study. The themes are: University Closure, Disruptions in Learning, Loss of Social Interaction, Physical Health Problems, Mental Health Problems, Shifting to Online Education, and Financial Crisis and Parental Involvement. The data portrayed below according to the themes.

\subsection{University Closure}

COVID-19 had spread all over the world since January 2020. When several suspicious cases started coming up in Bangladesh, the government announced that all educational institutions should be closed. All participants expressed that at first, they were unprepared and shocked by this abrupt announcement of closure, but later they understood the urgency of the decision in the COVID-19 crisis. Due to the announcement, libraries, seminars, residential halls were closed immediately. The students living in the university residential halls had to leave the campuses and rush towards their hometowns or villages on short notice. So 
they could not even take all the necessary things with them. The entire academic and official activities of their universities were ceased abruptly. The students were unhappy, unsure and worried about their studies, classes, examinations, results and stressed and concerned about session jam. One of the participants expressed:

Suddenly the university, the class all closed without any indication before. I used to study regularly according to what the teachers teach in the class; follow lectures; do assignments and presentations. Now the class is not happening, so the study has stopped. Though I understand the present situation of crisis, I am afraid that it would put us into a long session jam. $\left(\mathrm{P}_{7}\right)$

\subsection{Disruptions in Learning}

The participants were found experiencing several learning disruptions. They responded that they did not feel any motivation to study at home as there was no need to follow any scheduled routine for study and going to the university. So they spent ample time in doing some of their favorite works like farming, painting, gardening, handicrafts. They were also engaged in various non-academic activities: cooking, watching movies, TV, videos on YouTube, reading stories or holy books, doing social work or religious activities, spending time on social sites of Facebook, Instagram, etc. Few of them $(\mathrm{N}=3)$ were excited doing some free Massive Open Online Courses (MOOC) from different websites like Coursera, edX, FutureLearn, etc. A participant said:

I was under the stress of studying for an extended time. After a long time, I got a little free time. I am involved in different arts in this period. I cook different food items by following different recipes on Youtube. I feel delighted. I think I will take cooking as my profession. $\left(\mathrm{P}_{10}\right)$

Despite passing the time in such works, they all agreed to the fact that they became reluctant about their studies. They could not even remember the topics they already read in classes, and also they gradually lost the urge to learn new academic lessons. Some of them responded that due to the sudden closure of the university, they could not bring all their academic books and learning materials from the halls or living places. They added that some books were expensive to buy so that they used to read the books from the library. As they did not have the books in hand, so they could not learn academic lessons if they wanted to. Fifteen students complained about their home environment for not being suitable to study. One of the participants commented, "My house is noisy. So I could never study at home. I used to study at the library or seminars in my department. I have been home for a long time now, but I cannot read". The other students having academics books as well as the home environment to study also mentioned the decline in their study time, and the study time was daily for about one hour or less than that. They added that this university closure due to the pandemic interrupted their routine of study. Only a few of them $(\mathrm{N}=2)$ said 
that they enjoyed this temporary break from academic learning.

\subsection{Loss of Social Interaction}

Almost all the participants responded about missing their campus environment and social interactions with friends and teachers so much. They replied that they were used to do the group study with peers for solving academic problems and discuss or debate on different topics with friends. They generally preferred studying with peers on campus than studying alone at home. But due to the present circumstance, they had not seen their friends and classmates for a long time. They were unable to contact them regularly, which interrupted the peer-learning process. Though sometimes they talked over the phone or social sites, all of them admitted that lack of physical appearance made the conversations uninteresting. They also missed the previous interactions with teachers for study purposes or any other relevant matter. It was found that less social interactions with friends and teachers disrupted their motivation to study as one participant responded:

I used to study with my friends. It takes less time to understand many difficult issues or eliminate the dilemma of any study matter in group study. Due to this CORONAVIRUS pandemic, group study is not possible now, and as a result, I have lost my motivation to study. $\left(\mathrm{P}_{43}\right)$

One female student mentioned that it would also be a cause of communication barriers in the post-pandemic situation. She said:

I am staying at home without going out for a long time. I cannot talk to my friends regularly and do fun with them like before. I feel upset about that. It already hampered my habit of study with them. Nowadays, because of this home quarantine, I do not even like to converse with anyone spontaneously. I think in this way, most of us would forget to open up freely with each other, which can cause the communication gap in post-pandemic time. $\left(\mathrm{P}_{34}\right)$

\subsection{Physical Health Problems}

The researchers found that many changes took place in the participants' daily routines due to COVID-19. They said that their sleeping, eating, and working habits changed so much, such as an increase in sleep during the day, lack of sleep at night, loss of appetite, physical inactivity, which resulted in weight gain or obesity. They felt weakness, fatigue, and so on. The majority of the participants identified these physical problems as reasons for ignoring and not being enthusiastic about continuing their studies at home, which created distance from their academic education and hampered the flow of study. One male participant said:

I used to be very busy. Now, I am getting fat by eating food and staying at home all day. The body senses very weighty, the head tingles, feel giddy; 
there is a sluggish sensation. Is it imaginable to study in this condition? $\left(\mathrm{P}_{25}\right)$

One female student described:

The home quarantine is impacting on my health. I have Polycystic Ovarian Disease (PCOD). It does not have any permanent cure. I need to live on maintaining the right diet and do adequate exercise. When the university was open, I used to be on some physical movements all day long. So my physical problem was in a minimal position. But now my daily routine has changed. I am getting fat, which is increasing my physical problem a little bit. In this situation, I am not able to concentrate on my studies. That's why I am so upset about this pandemic situation. $\left(\mathrm{P}_{50}\right)$

\subsection{Mental Health Problems}

Stress was the most mentioned mental health problem by the respondents. They were found under a lot of pressure, not only thinking about COVID-19 situations but also for their academic education. Along with the fear of being infected with COVID-19, most of the participants felt anxiety for the factors like being scattered, less motivated, unable to adapt new academic habits in this situation. Uncertainty was working among the participants about the re-opening of class and examination-time, the publication of results, and promotion in a new academic year. They were also concerned about the post-pandemic situation that when the pandemic situation would be under control, there would be huge pressure on them to complete the course contents quickly. So the fundamental purposes of courses might not be fulfilled.

Some of the participants were frustrated thinking about their future. They felt anxiety and disappointments for not being able to complete their last year of graduation timely. The pandemic situation increased their stresses of getting jobs and being established. They thought that this prolonged academic year would delay their chances of getting jobs early and would also make job competition harder for them after graduation. They were in fear of crossing the specific age limit for employment in Bangladesh without securing one. A participant described:

Most government and private jobs in Bangladesh have a specific age limit for employment. In many cases, the subjects of the job examinations are entirely or partially different from the academic curriculum. I am not graduated yet, and the academic year is extending for this COVID-19. So when I would be able to take job preparation, I don't know. The economic recession has already started all over the world due to this pandemic. As a result, job opportunities would also be limited in recent years. I am now doubtful about my future and self-worth and afraid too of crossing the age limit for employment as my age is increasing. Since I have to take my family's responsibility, it would be better for me to get a job as early as possible. Now, 
I always feel very restless and cannot think of any matter deeply. Anxiety, frustration is consuming me in such a way that I am no longer interested in anything, not even study. $\left(\mathrm{P}_{5}\right)$

Some female participants were under another personal stress. Their families were pressurizing them for getting married without completing their graduation as no one could tell when the pandemic situation would recover and when they would complete their studies. The thought of marriage before graduation made them depressed and also deteriorated their moods of study.

\subsection{Shifting to Online Education}

Considering the prolonged closure of universities and the uncertainty of re-opening, some of the participants $(\mathrm{N}=7)$ regarded the Bangladesh government's decision of switching onto online tertiary education from conventional face-to-face education as a necessary one. The other participants could not appreciate the decision. They explained that online education would not be the best way to use for teaching-learning in the context of Bangladesh as many universities did not have enough resources for running online education urgently. The participants also said that while some teachers tried to take online classes on their initiatives, they faced some issues regarding virtual learning courses on online platforms. Some of them had no electronic devices such as computers, laptops, smartphones, or tablets to take part in online classes and no internet access at home. Some experienced low speed or no speed of the internet or frequent power cut problem in rural or town areas, some complained about the high cost of the internet. One of the participants commented:

There are many hassles of participating in online classes. In the village where I live now, the speed of the internet is too slow, power goes out after a while, and the internet cost for online classes is much higher. Neither my

family nor I can afford that now. $\left(\mathrm{P}_{11}\right)$

Many of the participants admitted that they were not skilled enough to use electronic devices for online classes. Those who were competent to run electronic devices smoothly, they also complained about the interruption of internet connection, while attending classes on Zoom, Google Meet, Google classroom, Skype platforms and also admitted their unfamiliarity to the functions of these platforms. Few students also said that their teachers were not adequately prepared for taking online classes. Some teachers had not much knowledge about how to conduct online courses and universities also did not have their effective online learning management systems. Participants also expressed many lab-based or practical work-based contents could not be clearly understood through online classes, and they did not get enough time to respond to any online test.

All the participants experiencing online classes expressed that they would prefer face-to-face classes over online classes, as they did not feel connected to 
the online classes much. They felt boredom, sleepiness, uninteresting, and even they were unable to interact or discuss study matter flawlessly due to internet connection problems, which obstructed their concentrations. They indicated online learning was not as effective as they thought it would be before. Instead of that, it turned into a matter of new stress for them, which decreased their confidence levels. It also caused physical problems like headaches, backache, eye-strain, and ear-pain to them.

Participants also highlighted their difficulties in maintaining regular time schedules of online classes. They explained that their family members were not used to see them taking online classes. The family members did not understand their obligations related to the online classes. Participants experienced interferences in continuing their homework, setting learning times, convincing family members to keep a proper home environment for study, and keeping themselves motivated to learn through online education. In these circumstances, some of the respondents expressed their inability to take part in distance learning courses. A female participant mentioned:

I have been home for a few months. After a long time, I am spending a lot of time together with my family. My parents put pressure on me to do household works all day. After finishing those works, I find no more time and energy left for my study. So I feel like quitting from taking online classes. $\left(\mathrm{P}_{21}\right)$

After experiencing all these issues related to online class shifting in Bangladesh, all the participants agreed to one point that if the concerns regarding online education would not be mitigated, then the substantive purpose of it would not be gained. It would negatively affect their academic education and also demotivate their ability to learn.

\subsection{Financial Crisis and Parental Involvement}

Due to COVID-19, most of the respondents spoke about the financial crisis, which impacted on their studies. They described the situation that many of them lived off some tuitions or part-time works for bearing their expenses. In this time of the pandemic, all tuitions or part-time jobs stopped. Even their family income significantly reduced as COVID-19 already hit hard the economy of the world as well as Bangladesh. As the participants had to depend on their families for daily needs, it was a burden for them to manage extra money for buying internet packages with the high cost to attend online classes.

Two participants from private universities said that their parents showed incapability to bear the expenditure of their new semester running online. So due to lack of money, they could not pay for the new semester and were compelled to drop the semester heartbreakingly, which created a study gap.

Even a few participants $(\mathrm{N}=5)$ from public universities were also tensed as they were unable to attend online classes regularly buying internet packages because of their poor economic status. They were in thought that they would fail in 
course examinations due to this reason, and then they might be drop out of the academic year.

\section{Discussion}

COVID-19 has spread its effects on the teaching-learning process of primary, secondary and tertiary levels in Bangladesh. Various unprecedented social distancing measures taken by the government of the country to prevent the transmission of the disease, including the closure of educational institutions and switching to virtual education, have affected the education system and students' lives to a great extent. The present qualitative study highlighted the impact of COVID-19 pandemic on tertiary level of education in Bangladesh from the students' perspectives.

The current study showed that the participants were unhappy and unsatisfied; instead, shocked by the quick decision of countrywide closure of educational institutions, which concurred with the results of the previous studies (McCoole et al., 2020; Kedraka \& Kaltsidis, 2020). It was also found in the study that the prolonged university closure and home confinement due to COVID-19 caused immense disruptions in the students' learning, which were parallel to the findings of several studies such as interruption in the daily routine of life and study (Kedraka \& Kaltsidis, 2020), no access to the university library for issuing academic books, and lack of learning materials at home and disturbance in the home environment (Owusu-Fordjour et al., 2020), complexity to remember read lessons, decrease in overall study time and deterioration in motivation and concentration to study subject contents at home (Meo et al., 2020).

The present study findings also revealed that this pandemic caused a massive loss of social interactions. Group studies are essential for making concepts easier and academic development (Owusu-Fordjour et al., 2020). But students' regular group studies with peers in libraries or university campuses, face-to-face communications, and social interactions with friends and teachers faltered due to the pandemic, which can disrupt their motivations to learn at a high level. Students were found spending more time on social sites like Facebook, Instagram, and watching TV, movies, videos on Youtube, playing computer, or mobile games, which were also found in the previous studies (Al-Tammemi et al., 2020; Pan, 2020). Along with that, the university closure gave few students a break from academic learning. They utilized the time at home doing some online courses on Coursera, edX, FutureLearn websites or doing some of their favorite works like cooking, painting, and so on.

However, physical health is often associated with students' cognitive acts and academic performance (Dewa \& Lin, 2000). This study disclosed some physical health issues originated due to staying at home: an increase of sleep during the day, lack of sleep at night, loss of appetite, physical inactivity, weight gain or obesity, feeling of weakness, giddiness, fatigue, sluggish sensation. All of these hampered students' flow of study and decreased their enthusiasm for education. 
Shaw et al. (2015) similarly noted that different types of educational problems are observed when students have low physical fitness.

Again, the rapid proliferation of COVID-19 is accompanied by moderate to severe self-reported depressive and anxiety disorders in the general population (Wang et al., 2020). The current study highlighted some mental issues about students' health and academic education which were created by the COVID-19. Delay in studies, examinations, results, and promotions to new classes raised stress in students. Cao et al. (2020) also found this result in their research. In this study, the thoughts of extending the academic year and session jam, crossing the age limit of employment, rising of competition, and hardship in getting jobs after graduation, losing job opportunities in this time of economic recession developed uncertainty, frustration, disappointment, anxiety and stress in students. Because of this uncertain situation, some female participants were in extra pressure of getting married soon before graduation, which made them emotionally vulnerable. It can be forecasted that the students' mental state in the pandemic would affect their education in the future because academic achievements are influenced by students' negative emotions and hinder the progression of learning (Valiente et al., 2012).

Furthermore, in this pandemic crisis, online education has emerged as an immediate alternative to the traditional tertiary education system around the world, even in Bangladesh. Though online learning has its share of issues, it is a popular innovative method for providing education (Wallace, 2003). The present study identified several common problems concerning online education in Bangladesh. The comprised problems were: the absence of electronic devices like laptops, smartphones, computers, and tablets which are compulsory for online courses, limited or no access to the internet, high cost of mobile internet packages or broadband connections, interruption in online classes because of low speed or no speed of the internet and frequent power cut problem in rural or town areas. These findings were in accordance with the results of previous studies (Adnan \& Anwar, 2020; Arnhold et al., 2020; Kedraka \& Kaltsidis, 2020; Mahdy, 2020; Ramij \& Sultana, 2020). This unequal access to technical devices and the internet can impede the actual purpose of active learning through online classes (Xu \& Xu, 2019) and cause a digital divide in education.

Moreover, this study indicated the factors could hamper students' online academic education: lacking in skills of using technical devices, unfamiliarity to the functions of the online class platforms like Zoom, Google Meet, Google classroom, Skype, not having effective learning management systems and other essential equipment in universities, lacking in the quality of education, no or little preparation of teachers for running online teaching. According to the students of the study, several difficulties were linked to online learning in these areas: maintaining time schedules of online classes, setting times for homework, collecting learning materials due to online access blocking of many libraries, learning lab-based or practical work-based lessons, convincing family members to 
keep a proper home environment, solving online tests with short time, interacting with peers and teachers. All these issues associated with online education were also analogous to many pieces of literature (Adnan \& Anwar, 2020; Arnhold et al., 2020; Kedraka \& Kaltsidis, 2020; Mahdy, 2020). This study also showed that online education developed physical problems like headaches, backache, eye-strain, and ear-pain among students due to access use of laptops, smartphones, and earplugs for remote learning classes. It seemed to new mental stress to the students. Hand (2018) also reported that extensive use of technology for online learning could negatively impact the physical and mental health of students. Because of the above issues related to online education, online classes seemed too dull, uninteresting, unattractive, unsatisfactory, and ineffective to the participants in this study and they preferred conventional face-to-face classes over online classes. This finding was entirely consistent with the findings of previous studies (Adnan \& Anwar, 2020; Kedraka \& Kaltsidis, 2020; McCoole et al., 2020; Tratnik et al., 2019).

Further, economic status plays an immense role in higher education as financial aids can help students to attain a better quality of education (Shaw et al., 2015). The findings of the current study also elicited that students' mental health and study were severely affected by financial factors: losing tuitions or part-time jobs, being incapable of bearing the expenditure of new online classes, reduction in parents' income due to the COVID-19 pandemic, being drop-out of the academic year or semester due to lack of money. These findings were corresponding to the conclusion made by (Chandasiri, 2020), which was pay-cuts or losing jobs, and parents' lower-income would impact the mental health and study of students.

All the data found from the analysis of seven themes portrayed the severe impact of COVID-19 on tertiary-level education in Bangladesh. Digitally advanced countries can provide effective online learning (Basilaia \& Kvavadze, 2020), and developing countries with limited technical resources face many challenges in implementing online education (Aldowah et al., 2019). As a developing country, the scope of online education is still low in Bangladesh. The students and universities here still have limited technical facilities. Without solving the issues concerning online education in Bangladesh stated in the study, active online learning is impossible. So it is recommended to provide necessary equipment like electronic devices, free or cheaper internet package to tertiary-level students during the COVID-19 pandemic period. Also, immediate actions should be taken for improving internet speed, creating learning management systems in universities, and providing technical training for students and teachers on online education. Study groups of students on online platforms can also be made to interact and learn lessons with enjoyment. The social relationship among students, teachers and family members should be strongly formed. Thus, the students' educational disruptions, physical, mental problems, and economic pressures can be lessened to some extent in this critical time of COVID-19 pandemic. 
However, this study had some limitations regarding the sample size. Despite such limitations, the information provided by this research might be useful for the educationists and Ministry of Education in Bangladesh to prepare plans for combatting adverse impacts of crises like a pandemic on education field. This research also gave insights into future investigations on the effects of COVID-19 on the tertiary level of education. Similar studies could be conducted with a large sample size in various sample sites. Moreover, the perspectives of teachers and other stakeholders of tertiary education could also be incorporated into further researches. Even the quantitative analysis with large samples regarding this topic can also be done for generalization of the outcomes.

\section{Conclusion}

COVID-19 outbreak has spread its adverse effects on students' education, including health, economy, and societal relationship. The measures like social distancing, quarantine, closure of educational institutions taken to reduce the transmission of the disease have impacted students' academic learning to a great extent. The significant effects of this pandemic have crippled the conventional tertiary education system. Students at the tertiary level have fallen into a massive problem about their future. The current study shed light on the impacts of COVID-19 pandemic on tertiary level education in Bangladesh from the perspectives of university students. It showed that the learning disruptions, difficulties in social interaction, physical and mental health problems, economic crisis, caused by the outbreak of COVID-19, had discrepant consequences on tertiary students' academic education and learning behaviors. This study also highlighted that shifting to online education for continuing tertiary education created stress, anxiety, disappointment due to some unavoidable issues concerning virtual learning strategy. The findings of this qualitative study would help the students, teachers, educationists and government officials associated with tertiary-level education in Bangladesh to obtain an in-depth understanding of the numerous impacts of COVID-19 on tertiary education. Supports from the family, friends, and government are needed to minimize the social, physical, mental, and educational disruptions of students. It is recommended that urgent steps should be taken to provide technical resources and improve internet connection for ensuring uninterrupted online education in Bangladesh to fulfill the education needs of tertiary level students in this crisis period of COVID-19 pandemic.

\section{Conflicts of Interest}

The authors declare no conflicts of interest regarding the publication of this paper.

\section{References}

Adnan, M., \& Anwar, K. (2020). Online Learning amid the COVID-19 Pandemic: Students' Perspectives. Journal of Pedagogical Research, 1, 45-51. 
https://doi.org/10.33902/JPSP.2020261309

Ahmed, M. (2020). Tertiary Education during Covid-19 and Beyond. The Daily Star. https://www.thedailystar.net/opinion/news/tertiary-education-during-covid-19-and-be yond-1897321

Aldowah, H., Al-Samarraie, H., \& Ghazal, S. (2019). How Course, Contextual, and Technological Challenges Are Associated with Instructors' Individual Challenges to Successfully Implement E-Learning: A Developing Country Perspective. IEEE Access, 7, 48792-48806. https://doi.org/10.1109/ACCESS.2019.2910148

Al-Tammemi, A. B., Akour, A., \& Alfalah, L. (2020). Is It Just about Physical Health? An Internet-Based Cross-Sectional Study Exploring the Psychological Impacts of COVID-19 Pandemic on University Students in Jordan Using Kessler Psychological Distress Scale. https://doi.org/10.1101/2020.05.14.20102343

Arnhold, N., Brajkovic, L., Nikolaev, D., \& Zavalina, P. (2020). Tertiary Education and COVID-19: Impact and Mitigation Strategies in Europe and Central Asia. http://pubdocs.worldbank.org/en/783451590702592897/ECA-TE-and-COVID-19-long -FINAL-25May20.pdf

Basilaia, G., \& Kvavadze, D. (2020). Transition to Online Education in Schools during a SARS-CoV-2 Coronavirus (COVID-19) Pandemic in Georgia. Pedagogical Research, 5, em0060. https://doi.org/10.29333/pr/7937

Braun, V., \& Clarke, V. (2006). Using Thematic Analysis in Psychology. Qualitative Research in Psychology, 3, 77-101. https://doi.org/10.1191/1478088706qp063oa

Brooks, S. K., Webster, R. K., Smith, L. E., Woodland, L., Wessely, S., Greenberg, N., \& Rubin, G. J. (2020). The Psychological Impact of Quarantine and How to Reduce It: Rapid Review of the Evidence. The Lancet, 395, 912-920. https://doi.org/10.1016/S0140-6736(20)30460-8

Burgess, S., \& Sievertsen, H. H. (2020). Schools, Skills, and Learning: The Impact of COVID-19 on Education. https://voxeu.org/article/impact-covid-19-education

Cao, W., Fang, Z., Hou, G., Han, M., Xu, X., Dong, J., \& Zheng, J. (2020). The Psychological Impact of the COVID-19 Epidemic on College Students in China. Psychiatry Research, 287, Article ID: 112934. https://doi.org/10.1016/j.psychres.2020.112934

Chandasiri, O. (2020). The COVID-19: Impact on Education. Journal of Asian and African Social Science and Humanities, 6, 37-42. https://www.aarcentre.com/ojs3/index.php/aarcentre/article/view/207/472

Charles, N. E., Strong, S. J., Burns, L. C., Bullerjahna, M. R., \& Serafine, K. M. (2020). Increased Mood Disorder Symptoms, Perceived Stress, and Alcohol Use among College Students during the COVID-19 Pandemic. Impact of Covid-19 Pandemic on Well-Being. https://psyarxiv.com/rge9k https://doi.org/10.31234/osf.io/rge9k

Creswell, J. W. (2013). Qualitative Inquiry and Research Design: Choosing among Five Approaches (3rd ed.). New York: SAGE Publications.

Dewa, C. S., \& Lin, E. (2000). Chronic Physical Illness, Psychiatric Disorder and Disability in the Workplace. Social Science \& Medicine, 51, 41-50. https://doi.org/10.1016/S0277-9536(99)00431-1

DiCicco-Bloom, B., \& Crabtree, B. F. (2006). The Qualitative Research Interview. Medical Education, 40, 314-321. https://doi.org/10.1111/j.1365-2929.2006.02418.x

Earn, D. J. D., He, D., Loeb, M. B., Fonseca, K., Lee, B. E., \& Dushoff, J. (2012). Effects of School Closure on Incidence of Pandemic Influenza in Alberta, Canada. Annals of Internal Medicine, 156, 173-181. 
https://doi.org/10.7326/0003-4819-156-3-201202070-00005

Hand, B. (2018). 3 Common eLearning Health Issues and How to Overcome Them. eLearning Industry. https://elearningindustry.com/elearning-health-issues-overcome-3-common

Institute of Epidemiology, Disease Control and Research (IEDCR) (2020). Covid-19 Vital Statistics. IEDCR. https://iedcr.gov.bd

Jacob, O. N., Abigeal, I., \& Lydia, A. E. (2020). Impact of COVID-19 on the Higher Institutions Development in Nigeria. Electronic Research Journal of Social Sciences and Humanities, 2, 126-135.

http://www.eresearchjournal.com/wp-content/uploads/2020/04/0.-Impact-of-COVID. pdf

Kawano, S., \& Kakehashi, M. (2015). Substantial Impact of School Closure on the Transmission Dynamics during the Pandemic Flu H1N1-2009 in Oita, Japan. PLoS ONE, 10, e0144839. https://doi.org/10.1371/journal.pone.0144839

Kedraka, K., \& Kaltsidis, C. (2020). Effects of the Covid-19 Pandemic on University Pedagogy: Students' Experiences and Considerations. European Journal of Education Studies, 7, 8. https://doi.org/10.46827/ejes.v7i8.3176

Luca, G. D., Kerckhove, K. V., Coletti, P., Poletto, C., Bossuyt, N., Hens, N., \& Colizza, V. (2018). The Impact of Regular School Closure on Seasonal Influenza Epidemics: A Data-Driven Spatial Transmission Model for Belgium. BMC Infectious Diseases, 18, 29. https://doi.org/10.1186/s12879-017-2934-3

Mahdy, M. (2020). The Impact of COVID-19 Pandemic on the Academic Performance of Veterinary Medical Students. https://doi.org/10.20944/preprints202006.0130.v2

McCoole, M., Boggiano, N., \& Lattanzi, O. (2020). Transitioning during COVID-19: Student Perspectives. Interactive Qualifying Projects (All Years).

https://digitalcommons.wpi.edu/iqp-all/5770

Meo, S. A., Abukhalaf, A. A., Alomar, A. A., Sattar, K., \& Klonoff, D. C. (2020). COVID-19 Pandemic: Impact of Quarantine on Medical Students' Mental Wellbeing and Learning Behaviors. Pakistan Journal of Medical Sciences, 36, S43-S48.

https://doi.org/10.12669/pjms.36.COVID19-S4.2809

Nicola, M., Alsafi, Z., Sohrabi, C., Kerwan, A., Al-Jabir, A., Iosifidis, C., Agha, M., \& Agha, R. (2020). The Socio-Economic Implications of the Coronavirus Pandemic (COVID-19): A Review. International Journal of Surgery, 78, 185-193. https://doi.org/10.1016/j.ijsu.2020.04.018

Owusu-Fordjour, C., Koomson, C. K., \& Hanson, D. (2020). The Impact of Covid-19 on Learning-The Perspective of the Ghanaian Student. European Journal of Education Studies, 7, 88-101.

Pan, H. (2020). A Glimpse of University Students' Family Life amidst the COVID-19 Virus. Journal of Loss and Trauma, 25, 594-597. https://doi.org/10.1080/15325024.2020.1750194

Ramij, M. G., \& Sultana, A. (2020). Preparedness of Online Classes in Developing Countries amid COVID-19 Outbreak: A Perspective from Bangladesh (SSRN Scholarly Paper ID 3638718). Social Science Research Network. https://doi.org/10.2139/ssrn.3638718

Shaw, S. R., Gomes, P., Polotskaia, A., \& Jankowska, A. M. (2015). The Relationship between Student Health and Academic Performance: Implications for School Psychologists. School Psychology International, 36, 115-134.

https://doi.org/10.1177/0143034314565425 
Tratnik, A., Urh, M., \& Jereb, E. (2019). Student Satisfaction with an Online and a Face-to-Face Business English Course in a Higher Education Context. Innovations in Education and Teaching International, 56, 36-45. https://doi.org/10.1080/14703297.2017.1374875

UNESCO (2020a). Adverse Consequences of School Closures. UNESCO. https://en.unesco.org/covid19/educationresponse/consequences

UNESCO (2020b). Education: From Disruption to Recovery. UNESCO. https://en.unesco.org/covid19/educationresponse

Valiente, C., Swanson, J., \& Eisenberg, N. (2012). Linking Students' Emotions and Academic Achievement: When and Why Emotions Matter. Child Development Perspectives, 6, 129-135. https://doi.org/10.1111/j.1750-8606.2011.00192.x

Wallace, R. M. (2003). Online Learning in Higher Education: A Review of Research on Interactions among Teachers and Students. Education, Communication \& Information, 3, 241-280. https://doi.org/10.1080/14636310303143

Wang, C., Pan, R., Wan, X., Tan, Y., Xu, L., Ho, C. S., \& Ho, R. C. (2020). Immediate Psychological Responses and Associated Factors during the Initial Stage of the 2019 Coronavirus Disease (COVID-19) Epidemic among the General Population in China. International Journal of Environmental Research and Public Health, 17, 1729. https://doi.org/10.3390/ijerph17051729

World Health Organization (WHO) (2020). Novel Coronavirus (2019-nCoV) Situation Report-1. WHO.

https://www.who.int/docs/default-source/coronaviruse/situation-reports/20200121-sitr ep-1-2019-ncov.pdf?sfvrsn=20a99c10_4

Wu, J. T., Cowling, B. J., Lau, E. H. Y., Ip, D. K. M., Ho, L.-M., Tsang, T., Chuang, S.-K., Leung, P.-Y., Lo, S.-V., Liu, S.-H., \& Riley, S. (2010). School Closure and Mitigation of Pandemic (H1N1) 2009, Hong Kong. Emerging Infectious Diseases, 16, 538-541. https://doi.org/10.3201/eid1603.091216

$\mathrm{Xu}, \mathrm{D} ., \mathrm{Xu}, \mathrm{Y}$. (2019). The Promises and Limits of Online Higher Education: Understanding How Distance Education Affects Access, Cost, and Quality. https://files.eric.ed.gov/fulltext/ED596296.pdf 